\title{
Abnormalities in the development of the second molars and orthodontic treatment without extraction of premolars. Management of posterior crowding
}

\section{H. Desnoës}

Practice at the CMS in Nanterre

\begin{abstract}
With the development of so-called "non-extraction"10 treatments in contemporary orthodontics, complications in the eruption of the second molars are becoming noticeably more prevalent in our practices ranging from a simple delay of eruption, to ectopic eruption, up to retention of the second molars caused by a mechanical obstruction. Using a retrospective study of some cases and a review of the literature, we are seeking to find new diagnostic approaches in order to choose the best treatment.
\end{abstract}

\section{KEY WORDS}

Premolar extraction, non-extraction, second molar impaction, mechanical retention/ blockage of the second molars, molar distalization, preservation of the space for mesial drift

\section{INTRODUCTION}

The consequences of non-extraction treatment on impaction of the third molars have been extensively studied, but there is still little research concerning the subsequent impact on the second molars of treatment to prevent mesial drift $^{12}$ of the first molars. Although low 0.2 to $2.3 \%$ of the general population according to the studies $^{27}$ ), it seems that the percentage of retained second molars has increased over the last few decades ${ }^{11}$. The various studies do not always make a distinction between the etiology of the delays or the failure to erupt. The delays may be due to ankylosis, a primary failure of eruption (or idiopathic failure to erupt) or because of a mechanical obstacle ${ }^{9}$. Studies show that with environmental modifications, the dento-maxillary discrepancies (DMD) tend to increase $^{8}$. But some authors are beginning to see a relationship between an increase in impactions of the second molars with 
the reduction in the rate of extractions of premolars in modern therapeutics $^{1,12,16,23,26,27}$.

After a brief statement on the effects obtained by the different appliances for anchorage preservation and their consequences on the impaction of the second molars, the arguments in favor of one or another treatment are discussed. Thus, patients, particularly those who believe that orthodontics can always be done without extractions, will have the relevant facts to give informed consent.

The choice to extract premolars or not in order to create the necessary space to align the anterior and median sectors and to allow the dento-alveolar compensations for the dysplasias is often dictated by the latest trends. The current tendency is to "avoid extractions as much as possible," averaging around $25 \%$ of cases treated with premolar extractions compared to $73 \%$ observed in the 1960's for all practitioners combined ${ }^{19}$.

It is sometimes difficult for the practitioner to make an irreversible decision in so-called borderline cases that can be treated in a variety of ways. The reason is that it not a simple equation with one unknown. In addition to the concrete values of crowding, we contend with the phenomena of growth that are not always predictable and that vary from one individual to another.

There are numerous articles on the esthetic, functional (occlusal, respiratory), periodontal, and psychological repercussions of treatment without the extraction of premolars. The management of the space in the posterior region, where crowding has been reported, will therefore be studied. Ideally, practitioners should have all the required tools before beginning treatment that help them know if the extraction of premolars or the wisdom teeth alone will be sufficient to provide the necessary space for placing all the teeth in the arch, or to predict if it is absolutely necessary to sacrifice eight teeth, one quarter of the total number of teeth.

\section{EFFECTS ON THE MANDIBULAR SECOND MOLARS OF THERAPIES FOR ANCHORAGE PRESERVATION OR MOLAR DISTALIZATION}

The available space provided by the difference between the mesiodistal diameters of the primary mandibular molars and the premolars is an average of $2.5 \mathrm{~mm}^{6,22}$ with strong individual variations ${ }^{32}$.

According to Gianelly ${ }^{15}$, 85\% of Class I and I| cases with crowding consisting of a maximum of between 6 and $8 \mathrm{~mm}$ can be treated by molar retraction that does not exceed $1 \mathrm{~mm}$.
There were no articles on a Class III case treated by maintaining the position of the mandibular molar. In these cases, perhaps the risk of impaction is significantly lower because the mandibular molar was more mesial?

Four recent studies begin to seriously link impaction of the mandibular second molars (M2) with techniques to conserve space for mesial movement. 
Shinora et al. ${ }^{26}$, without presenting any particular study have noticed that in their practice there is a net increase in simultaneous impactions of the second and third molars (M3) in adolescents.

For Sonis and Ackerman ${ }^{27}$, using a lingual arch to keep the first molars in their initial position multiplies by ten to twenty times the risk of impaction of the second molars as compared to the general population. In their study of two hundred cases, they observed a percentage of impaction of $8.5 \%$.

For Ferro et al. ${ }^{12}$, the use of the lip bumper $^{31}$ studied in 260 cases was found to show an increase in the percentage of impactions similar to that of the Sonis study (7\% against 1.4\% in the control group) as well as a strong increase in ectopic eruptions between 1.6 to $16.4 \%$. It emphasizes as well that, if the duration of the application does not exceed 9 months to 1 year, and if the braces are adjusted properly, a potential mechanical retention seems avoidable.
Finally, the study of Rubin et al. ${ }^{22}$ compared the effects of treatment with a Schwartz Plate, lingual arch or a combination of the two in 301 patients. The use of these two appliances, generated a higher rate of anomalies of eruption $(14.7 \%)$ as opposed to $7.8 \%$ with the Schwartz appliance and $4.7 \%$ with the lingual arch alone. Further, they show that, the longer the appliances are worn the more the risk of impaction increases.

In all these studies, no significant difference has been shown between boys and girls.

Would the extraction of premolars allow for the eruption of M3? Would the removal of $\mathrm{M} 3$ at the start of multi-banded treatment allow for the eruption of $\mathrm{M} 2$ before removing the appliances? The repositioning of $\mathrm{M} 2$ was impossible; the patient was discouraged and unfortunately didn't understand why it was necessary.

\section{EFFECTS ON THE MAXILLARY SECOND MOLARS OF THERAPIES TO MAINTAIN ANCHORAGE OR TO DISTALIZE THE MOLARS (FIGS. 1 AND 2)}

In the maxilla, there is considerably less leeway space than in the mandible; this could explain why there are fewer impactions of maxillary second molars for the most part in studies following the application of these therapies. A recent Cochrane analy$\operatorname{sis}^{17}$ gives an update on all the reliable studies comparing the intra-oral and extra-oral appliances for molar retraction or for at least maintaining molar position before the loss of the primary second molars. It shows that the intra-oral appliances allow for increased molar retraction but this increase is associated with a loss of anterior anchorage that is avoided with extra-oral forces (EOF). The quantity of studies is small as well as the level of proof. If these appliances are truly effective one might wonder if they have a significant effect on the eruption of the second molars. 


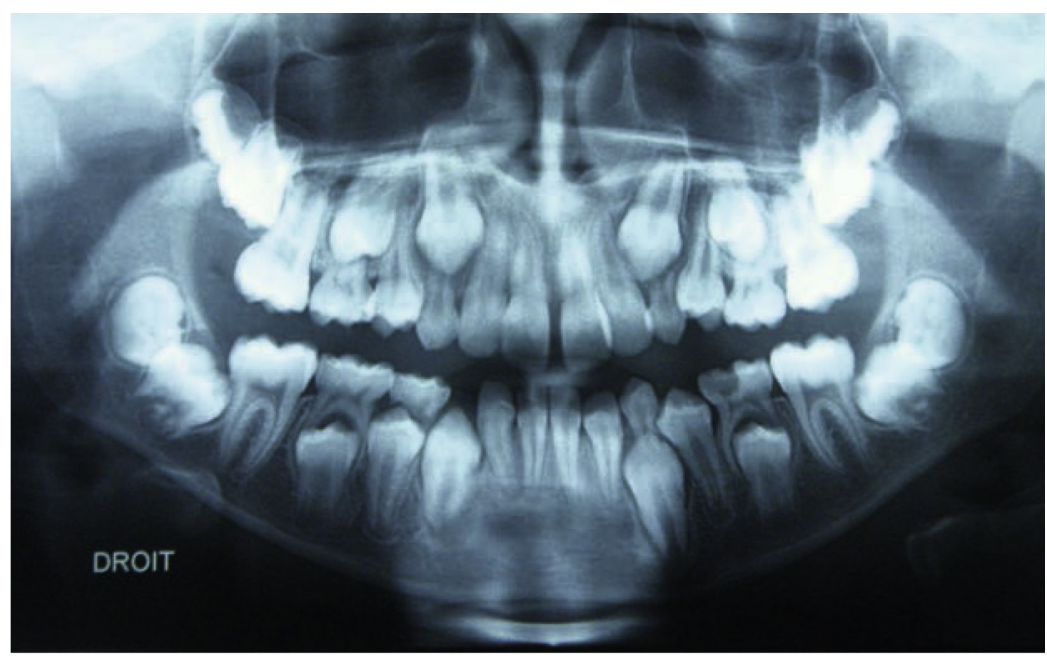

a

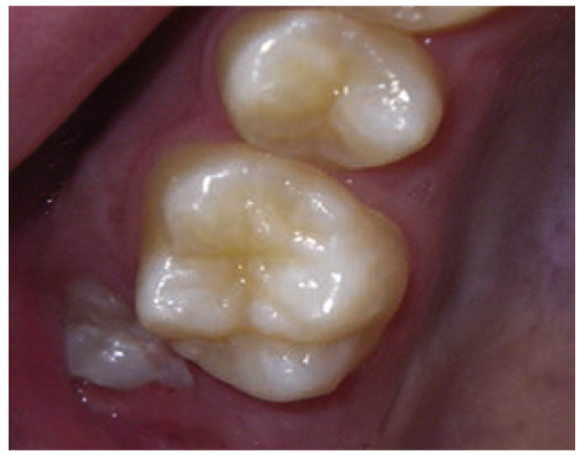

b

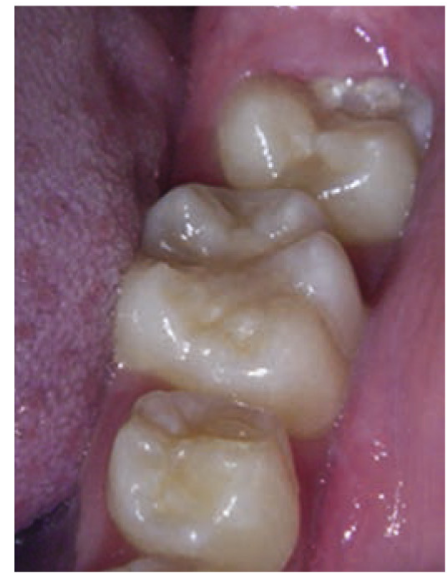

C

Figure 1

Marwann, without medical antecedents (ATCD). Mechanical retention of the four M2 following therapy with a lingual arch and straight wire (Roth). a) Radiograph at 12 years, dental age delay. b) and c) After extraction of buds of the $M 3$, late vestibular ectopic eruption of the $M 2$ in the maxilla and the mandible at 15 and one half years.

The pendulum appliances do not have a skeletal effect ${ }^{20}$ or only an effect limited to a greater opening of the mandibular compass (angle) if the application is late ${ }^{7}$ whereas the orthopedic effect of the EOF will not be very controversial ${ }^{19}$.

With the arrival of absolute anchorage provided by miniscrews, it will be truly possible to obtain even more significant molar retraction, and one can reasonably be apprehensive about an increase in the impaction of the second molars.

These appliances are currently being used before the second molars have yet erupted into the arch. Numerous authors ${ }^{20}$ have shown that the presence of second molars does not impede their action, the 


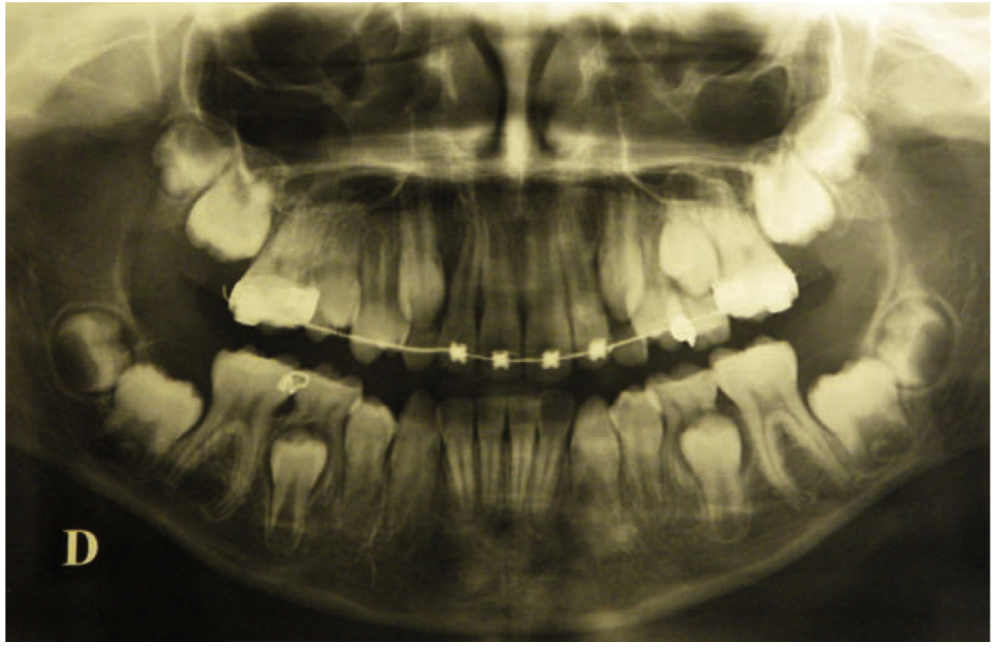

a

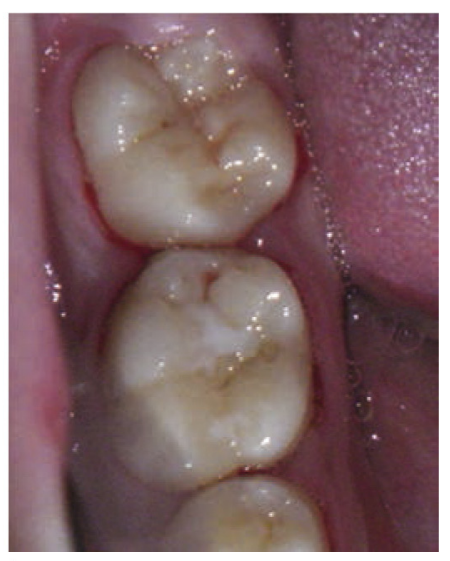

b

Figure 2

Yacine without any medical ATCD. Mesio-lingual rotation following therapy for maintenance of the leeway space. a) Panoramic radiograph at 10 years. b) Mesio-lingual rotation of 46.

retraction of the first molar occurs very slowly with the help of heavy forces but with a significant translational component. Perhaps it would be preferable under certain conditions to delay the start of the orthodontic treatment plan until the completion of eruption of the young adult dentition.

The application of distalization appliances on two molars at the same time leads to a greater loss of anchorage (that could be resolved by the use of miniscrews) as well as to buccal displacement of the second molars.

For many authors, there would be a complete relapse of tipping and maintenance of the orthopedic effects after interruption of the distalizing forces. The action of the mechanisms of extra-oral forces have been amply described in the literature, on the other hand their influence on the space for the eruption of the second molars has not been examined in detail.
According to Piva et al. ${ }^{24}$, maxillary molar distalization treatment displaces the pterygomaxillary fissure and appositional/resorption growth at the maxillary tuberosity thus compensating the absence of the mesialization of the first molars, and allowing the second molars to erupt without difficulty. It is not certain if the wisdom teeth will be impacted, the follow-up studies are ongoing.

Nanda and Dandajena ${ }^{23}$ present a case with a significant delay of eruption. After 6 years of wearing an EOF device the treatment was discontinued at 13 years of age, the M2 at 16 years had not yet erupted but were present in the arch at 21 years of age. This eruption that took place all the same but very late can be explained simply by the relapse of the obtained dental effects. Only the orthopedic effects were maintained over the long term.

There have been two recent studies on preservation of molar 


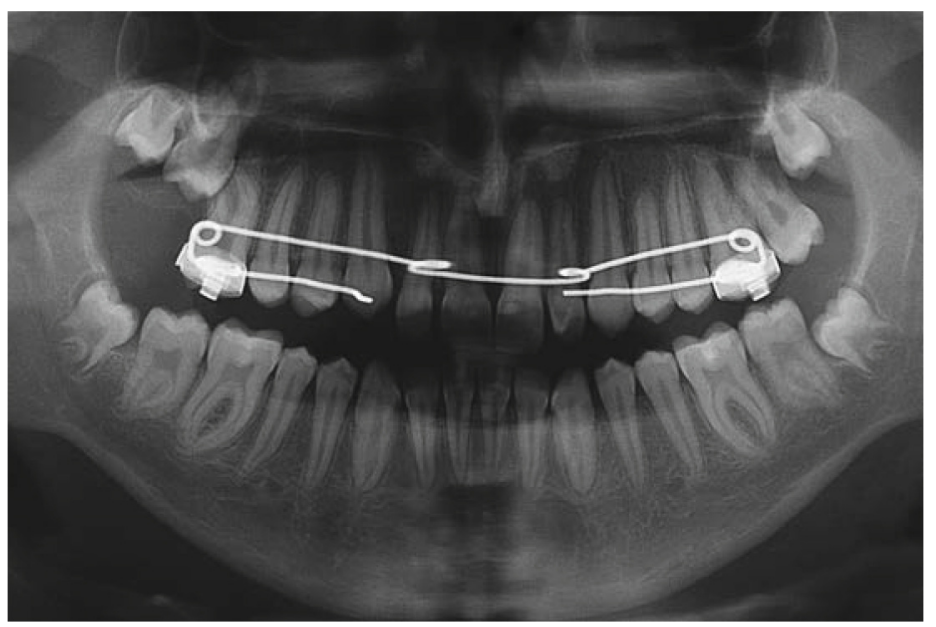

Figure 3

Mathieu: Unerupted 17 following molar de-rotation using a quad-helix.

anchorage, or distalization of the maxillary molars and the effects on the maxillary second molars. The study of Abed $^{1}$ involved 47 patients treated by EOF shows that the appliance induces a delay of eruption but not a mechanical retention (blockage). The study of Gour ${ }^{16}$ presents a case of retention (blockage) of 17 following treatment by the DAC of Aknin, that was studied in 60 cases: 30 treated with extraction of 14, 24, 35,45 and 30 treated by DAC. But the initial ALD is greater in the group that had extractions. The posterior crowding is judged statistically more significant $(+3 \mathrm{~mm})$ and the second molar is inclined more distally $\left(+8.8^{\circ}\right)$ in the group without extractions.
The different appliances that allow for molar distalization generally create $^{21}$ a distal inclination of the M1 that occurs naturally and blocks the vertical eruption of the second molar (cf. Fig. 3).

Therefore, in almost all the patients, a delay in the development of the second molars likewise hinders the beginning of the second stage of the two phase treatment.

We might then question whether or not a treatment started at the end of the mixed dentition treatment and not ended until 13 years of age is actually effective, and whether or not it is accompanied by iatrogenic risks (caries, resorptions, loss of cooperation ....).

\section{INFLUENCE OF PREMOLAR EXTRACTIONS ON GROWTH}

Do extractions, that eliminate a certain amount of osseous alveolar material and that reduce the growth of the arches, have an impact on the subjacent osseous structures? There is scant scientific data in the literature to back this hypothesis.

According to Kalwitzki ${ }^{18}$, extraction treatment affects sagittal growth of the skeletal structures of the 
orofacial complex with significant variations between individuals depending upon the dysmorphosis. In Class skeletal Class III cases, the effects are more pronounced in the mandible than in the maxilla. In either case, the alveolar effects are apparent. Moreover, in Class II cases, there are also visible signs of these effects on the basal bone.

A contrario, according to some authors, the therapies used to retract the molars also have orthopedic effects on the growth of the jaws ${ }^{6,30}$. The stability of these results is very controversial.

\section{INFLUENCE OF PREMOLAR EXTRACTION ON THE DEVELOPMENT OF THE SECOND MOLARS}

Many studies have been carried out in order to demonstrate the impact of premolar extractons on the development of the third molars when there are no appliances for anchorage support ${ }^{14}$. It seems logical to think that the effects are the same on the second molars. However, the conclusions of the studies are contradictory (since anterior and median initial crowding fluctuated), it would seem that it is particularly the

\section{CRITERIA OF DECISION}

The ratio between space available to mesio-distal diameter of the M2 seems to be an excellent indicator, the risk of impaction is increased in cases of posterior DDM but accidents of development of the M2 can also be produced in cases of agenesis of M3 if the angulation of the buds is significant (cf. Fig.4).

\section{Calculation of available space}

Presently, we do not have any specific indicators for assessing how much space is required for the removal of the second premolars that might have beneficial effects on the development of the M2.

When mandibular second premolars are extracted, the potential for the development of the wisdom teeth increased from 10 to $50 \%{ }^{14}$. But, in one out of every two cases, the treatment led to the extraction of 8 permanent teeth, in other words $1 / 4$ of all the teeth.

development of the maxillary second molars $^{16}$.

\section{Contribution of radiographic documents}

There is no possible way to measure the necessary space on a panoramic radiograph but it does help the practitioner evaluate the position of the tooth in relation to its neighbors and within the maxilla in the horizontal and vertical dimensions, as well as the degree of root development and the eruptive position. 


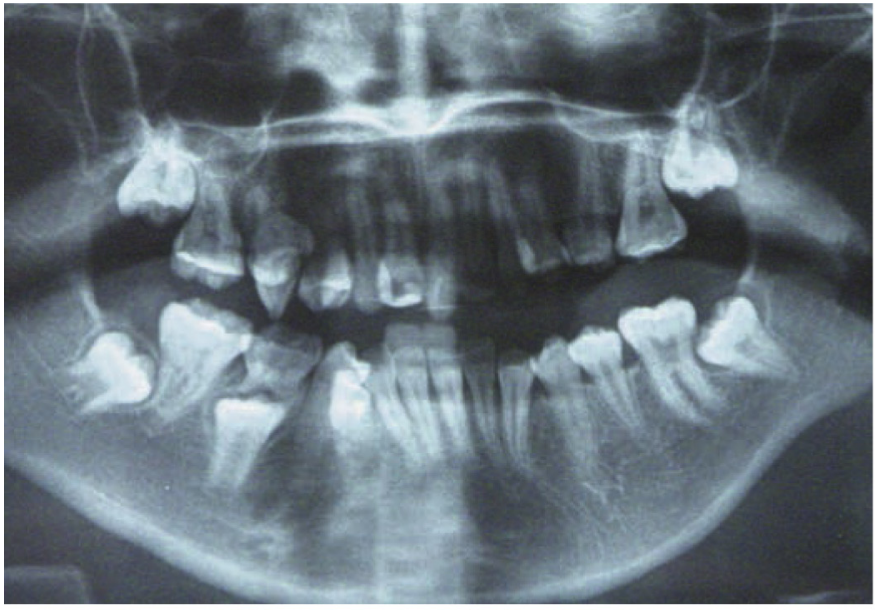

a

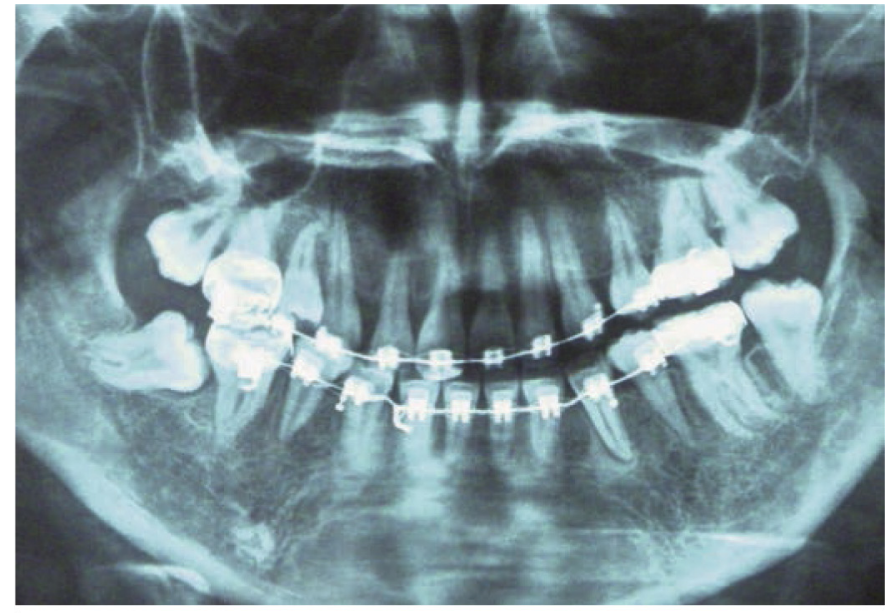

b

Figure 4

Sana: syndromic patient, mother had rubella during pregnancy. a) Panoramic at 15 years of age. b) Panoramic at 17 years of age.

It would seem that the evaluation of posterior space is more precise on a profile cephalometric radiograph than on a panoramic xray ${ }^{16}, 6 /$ PTV on the maxilla, opposite the distal surface of M1 mandibular at Ricketts $\mathrm{Xi}$ point $^{25}, 6-V_{L}{ }^{24}$ (cf. Fig. 5).

There are significant individual variations in the available space provided by the leeway space and it would be better to calculate it precisely $^{32}$ (rule of three [tripoding] with periapical films MOYERS ${ }^{15}$ ), before choosing this therapeutic pathway.

\section{- Potential for residual growth}

It is greater in boys than in girls. The works of Björk have shown that the jaws continue to grow for at least two years after the growth spurt that is later in boys.

\section{- Calculation of necessary space}

Nguyen $^{16}$ shows the cone beam can be used to measure the diameter of non-developed teeth with a margin of error of only $0.3 \mathrm{~mm}$.

\section{- Sexual dysmorphysm}

Dental morphology and the size of teeth $^{25}$, is more prevalent in girls.

According to the Tweed-Merryfield Guidelines those cases presenting with $5-6 \mathrm{~mm}$ of crowding are considered borderline 29 .

\section{- Angulation of the tooth buds before treatment}

The risk of impaction might be predictable by measuring the angle between the long axes of the first and second molars before treatment ${ }^{11,27}$. The practitioner should be careful in the therapeutic choices if this angle is greater than $24^{\circ}\left(30^{\circ}\right.$ according to Ferro ${ }^{12}$ ), and it would be preferable to extract premolars than to maintain the leeway space. 


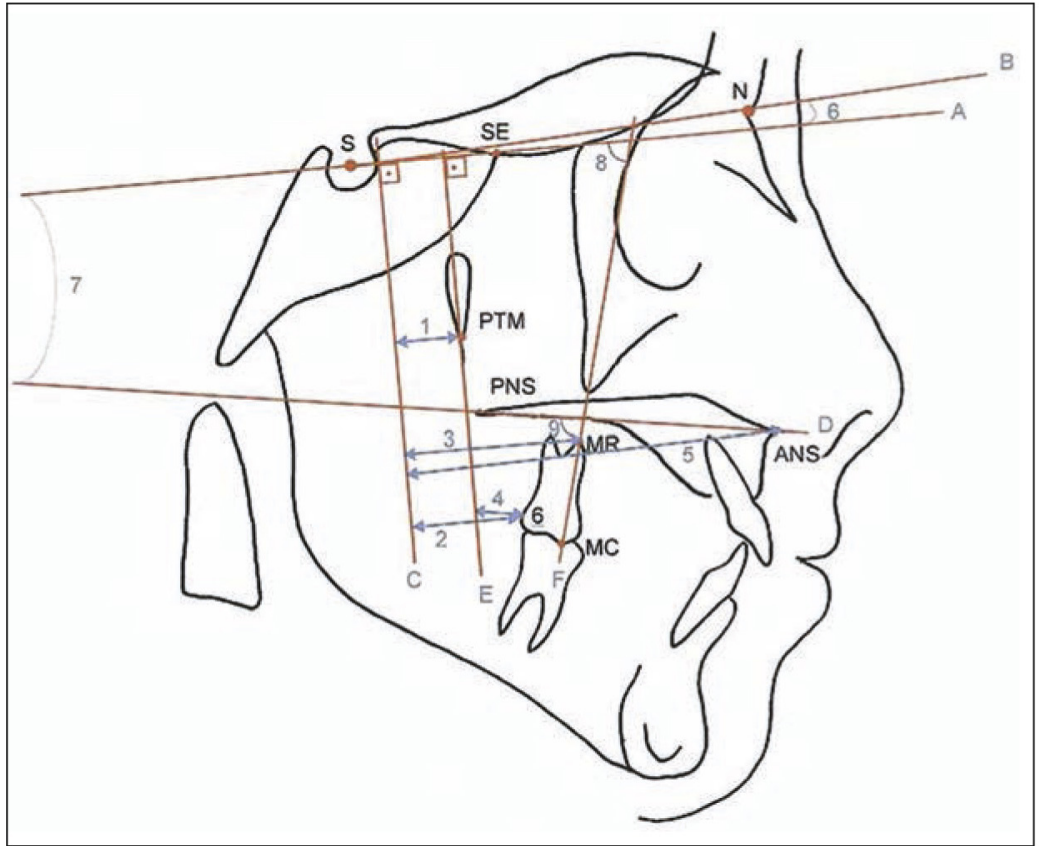

a

Figure 5

Cephalometric evaluation of the available space. a) In the maxilla after Piva ${ }^{24}$. Cephalometric lines = A: S-SE Line; B: S-N line; C: VRL (vertical reference line); D: palatal line; E: vertical PTM line; F: MCMR line (mesial cusp point of M1 - Mesial root apex of M1). Cephalometric parameters = 1: PTM-VRL distance; $2: 6-V R L ; 3: M R-V R L ;$ 4: 6-PTMvert; 5: ENA-VRL; 6: S-NAS-SE angle; 7: ENA-ENP^S-SE; 8. MC-MRAS-SE; 9: MC-MRAENA-ENP. b) In the mandible after Sable ${ }^{25}$. 1: mandibular angle (FH^Go-Me). 2: facial axis (Ba-Na^PtGn). 3: Condylion-Gnathion distance. 4: Articulare-Pogonion distance. 5: Xi-opposite distal M1 mandibular (D6) measured the length of the axis of the body (mm). 6: D6-symphysis (mm) (the most distal point of the lingual cortical bone). 7: Xi-symphysis (mm). b1) cephalometric measurements (1 to 4). b2) Cephalometric measurements 5 to 7 .

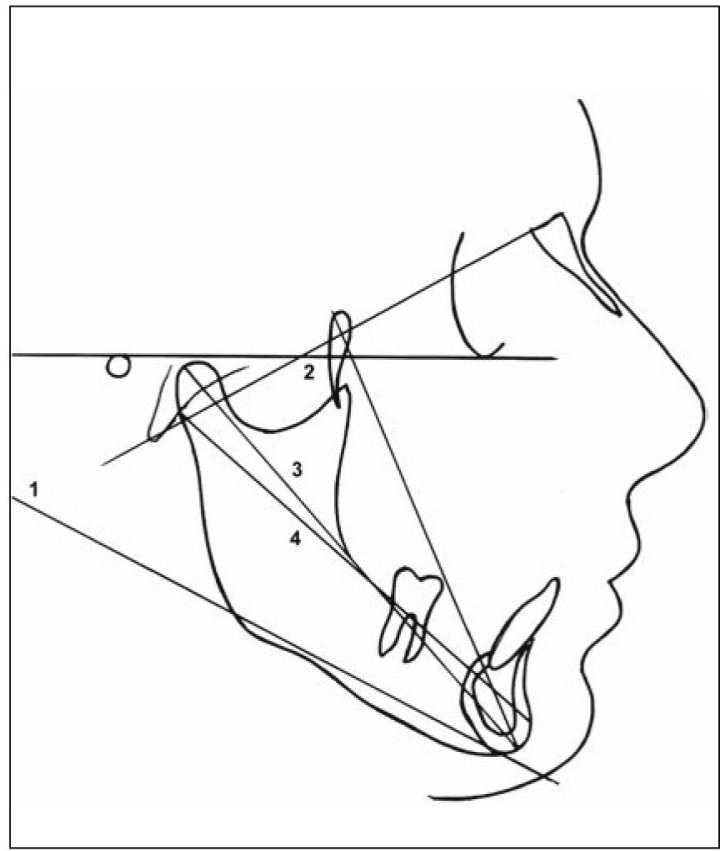

b1

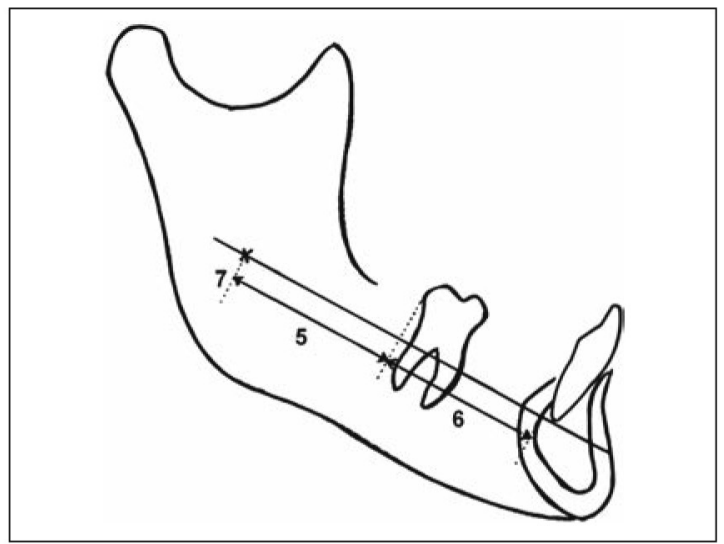

b2
However Lash Rubin, Baccetti and McNamara $^{22}$ do not think angulation is a predictable factor.

\section{- Presence of the buds of the wisdom teeth}

There is no study showing a link between the presence of the buds of
M3 and the risk of impaction of $\mathrm{M} 2^{27}$.

\section{- Status of development of the tooth} buds

The optimal time to wear EOF in order to avoid mechanical retention is determined radiologically. It is best to 
begin treatment when the crown of the upper $\mathrm{M} 2$ has erupted beyond $1 / 3$ of the apices of the upper $\mathrm{M}^{3}$.

Posterior growth is much greater in boys than in girls ${ }^{25}$.

\section{- Distal root curvatures? (cf. Fig. 6)}

There are no data found in the literature on this subject but this case as presented shows root curvatures associated with molar retention.

\section{ALTERNATIVES TO EXTRACTION OF THE SECOND PREMOLARS}

\section{Early removal of the wisdom teeth}

Recommended by Ricketts at 9-10 years of age, the removal of the buds of the wisdom teeth is attractive. It is done almost at the same time as the placement of anchorage. It therefore avoids mechanical retention of the second molars ${ }^{12}$. But there is no study showing a relationship between impaction of $\mathrm{M} 2$ and the presence of the bud of the M3. This solution has been very controversial but some authors ${ }^{4}$ show that this procedure includes psychological risks to minors and that, on the contrary, there is an increase in the technical difficulty of the procedure in the mandible with root development. Bjornland et al. have observed complications in $1.8 \%$ of cases in their study. From a surgical point of view, enucleations of the wisdom teeth would be relatively uncomplicated procedures, but the enucleations of the maxillary $\mathrm{M} 3$ are technically more difficult to $\mathrm{do}^{26}$. The question arises as to whether the premature removal of the $\mathrm{M} 3$ deprives the retromolar region of a significant potential for growth.

\section{Extraction of the second molars}

Anecdotally, some authors have called for the extraction of the second molar in cases of posterior crowding in order to allow for the natural development of the M3 with a satisfactory contact point ${ }^{13}$. With the new 3D imaging techniques, it will be possible to predict more precisely the shape of the third molars and thus to more easily make the decision to extract the M2.

\section{Transplatation of the buds of the M3 with the M2}

The transplantation of the buds of the $\mathrm{M} 3$ in place of the $\mathrm{M} 2$ can be planned $^{33}$.

After seeing the inclination of 38 , would the extraction of 37 have

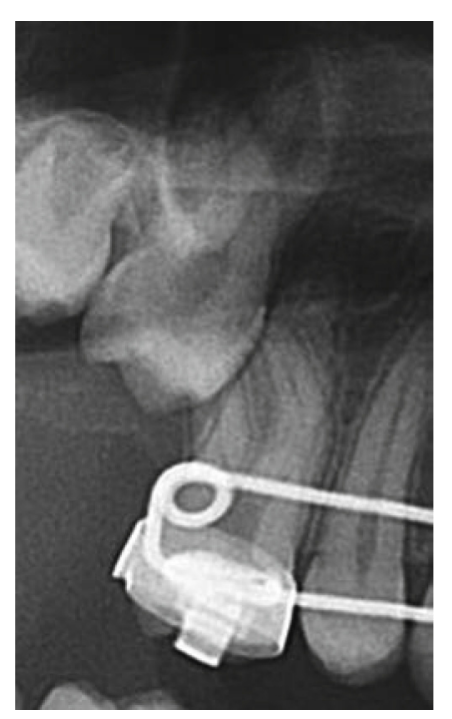

Figure 6 


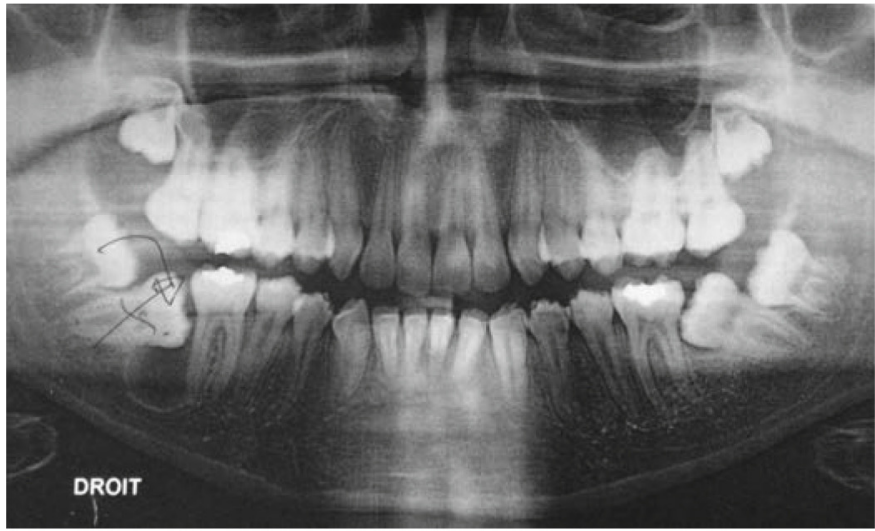

a

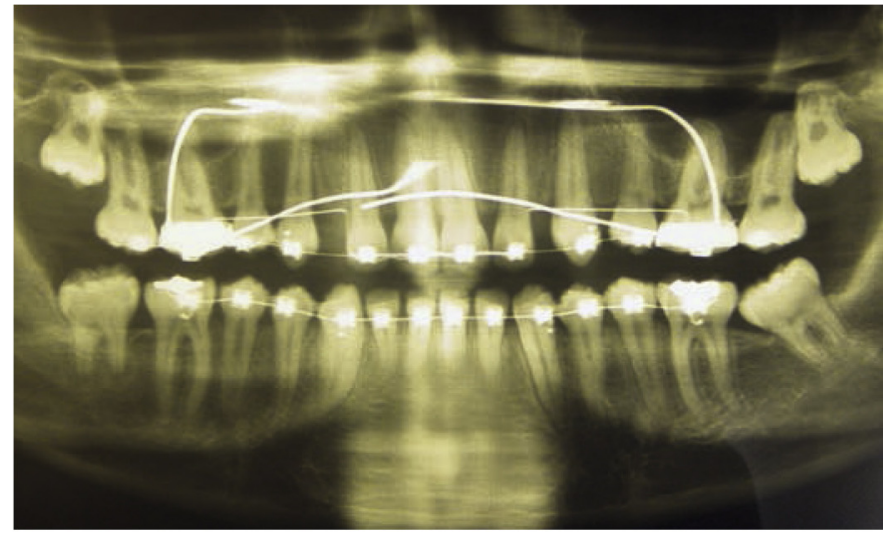

b

Figure 7

Yanis, without ATCD. a) panoramic at 15 years of age: impaction of 37 and 47 with strong mesial inclination. b) panoramic a 17 years of age: transplantation of $M 3$ in place of $M 2$, root development stopped. The 38 maintained its mesial version, the apexification was stopped at the time of the transplantation, and orthodontic alignment was judged too risky.

perhaps been better? (Fig. 7) The periodontal health of 37 that appears to be less precarious would have allowed for the application of orthodontic forces.

\section{CONCLUSION}

The point of this article is not to promote any particular technique. But it does seem legitimate to ask questions about the delay in the development or about the mechanical retention of the second molars following the utilization of techniques for anchorage maintenance or first molar retraction. The few studies on the subject show an increase in risks. But if the indications are clearly established and the appliances precisely controlled with well adjusted braces $^{12}$, and above all if the duration of the application does not exceed 9 months to 1 year, eventual mechanical retention seems to be avoidable. A good clinician does not have to be an extractionist or nonextractionist, he must possess good differential diagnostic skills as well as a certain artistic sensibility to make the right diagnostic decision ${ }^{29}$. Taking into account individual variation must be the rule and not the exception ${ }^{3}$. Let's not forget that one of our treatment objectives must be the placement of the second molars in the plane of occlusion.

It is important to consider the treatment plan criteria for the M2 from the start of the placement of the mechanics rather than two years later after multi-banded treatment has already been in progress.

We should not hesitate to reevaluate a case and to prescribe extractions after an unsuccessful interceptive first phase ${ }^{29}$, without forgetting to inform the patient of this eventuality in the 
course of the establishment of the treatment plan in borderline cases. We should not forget that extractions are irreversible.

According to the majority of authors, the degree of the molar retraction obtained with the distalization appliances of the maxillary M1 does not seem to be affected by the presence of the $\mathrm{M} 2^{7}$. Perhaps might it be better to wait for the development of the $\mathrm{M} 2$ in borderline cases? Conversely, it would seem that the opening of the mandibular angle could be greater in this option, where a potential contra-indication exists in hyperdivergent patients.

According to Vaden ${ }^{29}$, it is never detrimental to make a choice of extractions in borderline treatment cases. According to Bradley ${ }^{5}$, the choice of non-extraction treatment can be more problematic than with premolar extractions, and the stability would not be better. And further, the duration of active treatment in nonextraction of premolars is strongly increased $^{25}$. Since it started in the mixed dentition thus leading to a probable delay in the development of $M 2$, the treatment will end later than in cases with extractions, without forgetting what this implies in terms of iatrogenic and psychological risks.

According to Richardson ${ }^{2,32}$, it is rare for Europeans to have 32 teeth well aligned at the end of growth. It logically follows that if the premolars have not been extracted, then later on the wisdom teeth will be extracted $^{19}$.

Treatment beginning in the young adult dentition with newer techniques allowing for expansion using self-ligating brackets have not been discussed, it would be interesting to study their effects on distal crowding. Complimentary studies on the development on the second molars following the choice of treatment with or without premolar extractions with a homogeneous group of borderline cases, similar in sufficient quantity or with absolute anchorage appliances (existing adult study ${ }^{16}$ ) could be rewarding. Similarly, perhaps a statistical study on the age of the prescription of the extractions of the wisdom teeth could provide assistance in making decisions in our practices?

Of course, the recovery of an impacted second molar is quite feasible, after surgical exposure. Several appliances have been described to accomplish this. But it is advisable to notice the impaction early enough so that the patient does not refuse the procedure if and when cooperation changes over time.

Conflicts of interest: The author declares no conflict of interest.

\section{BIBLIOGRAPHY}

1. Abed Y., Brin I. Early headgear effect on the eruption pattern of maxillary second molars. Angle Orthod 2010;80(4):642-8.

2. Barthelemi S. Le site des extractions influence-t-il le profil ? Int Orthod 2014;12: 49-83. 
3. Bishara S.E. Class II malocclusions: diagnostic and clinical considerations with and without treatment. Seminars in Orthodontics 2006;12(1):11-24.

4. Bjornland T., Haanaes H.R., Lind P.O., Zachrisson B. Removal of third molar germs: study of complications. Int J Oral Maxillofac Surg 1987;16:385-390.

5. Bradley T.G. Changes in orthodontic treatment modalities in the past 20 years: exploring the link between technology and scientific evidence. $J$ of the Irish Dental Association 2012;59(2):91-94.

6. Brennan M.M., Gianelly A.A. The use of the lingual arch in the mixed dentition to resolve incisor crowding. Am J Orthod Dentofacial Orthop 2000;117:81-85.

7. Bussick T.J., McNamara J.A. Dentoalveolar and skeletal changes associated with the pendulum appliance. Am J Orthod Dentofacial Orthop 2000;117:333-43.

8. Camporesi M., Marinelli A., Baroni G., Defraia E. Dental arch dimensions and tooth wear in two samples of children in the '950s and '990s'. Br Dent J 2009;207(24):1-7.

9. Canut J.A., Ganda J.L. "Eruption incomplète des molaires permanentes : étude de 22 cas ". Rev Orthop Dento Faciale 1994;28:261-277.

10. Cetlin N.M., Spena R., Vanarsdall R.L. "Nonextraction Treatment " in Orthodontics Current Principles and Techniques, 5th edition, Elsevier, 2011, chap. 22, 785-805.

11. Cho S.Y., Ki Y., Chu V., Chan J. Inclusion des deuxièmes molaires permanentes chez des enfants d'ethnie chinoise d'âge scolaire. JADC 2008;74(6).

12. Ferro F., Funiciello G., Perillo L., Chiodini P. Mandibular lip bumper treatment and second molar eruption disturbances. Am J Orthod Dentofacial Orthop 2011;139: 622-7.

13. Gaumond G. Second molar germectomy and third molar eruption. Angle Orthod 1985;55(1):77-87.

14. Gebeile-Chauty S., Hekimian J., Aknin J-J. Évolution des dents de sagesse dans les traitements de cl II, 1 avec et sans extractions. Orthod Fr 2008;79:161-172.

15. Gianelly A.A. Crowding: timing of treatment. Angle Orthod 1994;64(6):415-8.

16. Gour C. Les traitements sans extractions des $\mathrm{Cl}$ II, 1 entraînent-ils des modifications de l'axe des secondes molaires maxillaires ? Mémoire de CECSMO Université Claude Bernard - Lyon 1, 2012.

17. Jambi S., Thiruvenkatachari B., O'Brien K.D., Walsh T. Orthodontic treatment for distalising upper first molars in children and adolescents. Cochrane Database of Systematic Reviews 2013;10: art n CD008375. DOI: 10.1002/14651858.pub2.

18. Kalwitzki M., Godt A., Göz G. Effects of extraction treatment on maxillary and mandibular sagittal development in growing patients. Eur J Orthod 2011;33:544-550.

19. Kandasamy S., Woods M.G. Is orthodontic treatment without premolar extractions always non-extraction treatment? Aust Dent J 2005;50(3):146-151.

20. Kinzinger GSM, Fritz UB, Sander FG, Dietrich P. Efficiency of a pendulum appliance for molar distalization related to second and third molar eruption stage. Am J Dentofacial Orthop 2004;125:8-23.

21. Kobayashi Y., Shundo I., Endo T. Treatment effects of quad-helix on eruption pattern of maxillary second molars. Angle Orthod 2012;82(4):676-81.

22. Lash Rubin R., Baccetti T., McNamara J.A. Mandibular second molar eruption difficulties related to the maintenance of arch perimeter in the mixed dentition. AJO-DO 2012;141(2):146-152.

23. Nanda R.S., Dandajena T.C. The role of the headgear in growth modification. Semin Orthod 2006;12(1):25-33.

24. Piva L.M., Brito H.H.A., Leite H.R., O'Reilly M. Effects of cervical headgear and fixed appliances on the space available for maxillary second molars. Am J Orthod and Dentofacial Orthop 2005;128(3):366-71.

25. Sable D.L., Woods M.G. Growth and treatment changes distal to the mandibular first molar: a lateral cephalometric study. Angle Orthod 2004;74:367-74.

26. Shinora E.H., Kaba S.C.P, Pedron I.G., Imparoto J.C.P. Bilateral lower second molar impaction in teenagers: an emergent problem? Indian J Dent Res 2010;21(2):309-10. 
27. Sonis A., Ackerman M. E-space preservation. Is there a relationship to mandibular second molar impaction? Angle Orthod 2011;81:1045-1049.

28. Tschechne S., Müller B., Dibbets J. Sagittal space relations in the maxilla during molar eruption. J Orofac Orthop 2008;69(2):94-8.

29. Vaden J.L., Kiser H.E. Straight talk about extraction and nonextraction: a differential diagnostic decision. Am J Orthod Dentofacial Orthop 1996;109:445-52.

30. Vanarsdall R.L., Secchi A.G., Chung C.H., Katz S.H. Mandibular basal structure response to lip bumper treatment in the transverse dimension. Angle Orthod 2004;74(4):473-9.

31. Werner S.P., Shivapuja P.K., Harris E.F. Skeletodental changes in the adolescent accruing from use of the lip bumper. Angle Orthod 1994;64(1):13-22.

32. Woods M.G. Mandibular arch dimensional and positional changes in late mixeddentition class I and II treatment. Am J Orthod Dentofacial Orthop 2002;122:180-8.

33. Yoshino K. et al. A retrospective survey of autotransplantation of teeth in dental clinics. J of Oral Rehab 2012;39:37-43. 